\title{
A IMPORTÂNCIA DAS LINGUAGENS ARTÍSTICAS NO DESENVOLVIMENTO INFANTIL
}

\author{
Fernanda Soares Godoi Yano do Canto ${ }^{1}$, Maria Cristina Ponçano Brito ${ }^{1}$, Carmen Lúcia Dias ${ }^{2}$
}

Discente do mestrado em Educação da UNOESTE. ${ }^{1}$ Docente do mestrado em Educação da UNOESTE. E-mail: godoyfefe@gmail.com

\section{RESUMO}

Este artigo tem por objetivo apresentar reflexões sobre as linguagens artísticas, que quando contempladas no desenvolvimento infantil contribuem para a formação inicial deste indivíduo. Para atingir tal objetivo, foi utilizada como metodologia a pesquisa bibliográfica onde autores expoentes na área propõem uma discussão acerca de questões pertinentes ao espaço ocupado pela arte e a música no campo da Educação Infantil. A inclusão das linguagens artísticas e os benefícios desta prática para a Educação Infantil são abordados e recomendados no Referencial Curricular Nacional para a Educação Infantil, indicando ser efetiva a presença das linguagens artísticas na formação integral da criança. Pensando na importância das linguagens artísticas para o desenvolvimento infantil, pretende-se analisar a importância do papel do professor como mediador de experiências transformadoras ao promover na criança a construção do conhecimento, bem como oportunizar o domínio das diversas linguagens, aguçar a criatividade, a imaginação e ampliar o seu desenvolvimento com o mundo que a rodeia.

Palavras-chave: Linguagens artísticas. Arte. Música. Educação Infantil. Ação docente.

\section{INTRODUÇÃO}

Pensar na contribuição que a utilização da Arte traz para a Educação Infantil abre uma reflexão sobre o eixo música e criatividade. Autores exploram o termo aprendizagem criativa em música, onde muitas possibilidades, a partir desta realidade, são passíveis de gerar desenvolvimentos às crianças de 0 a 5 anos.

Corroborando com a ideia, Beineke vem dizer:

a aprendizagem criativa em música pode indicar uma alternativa possível quando se deseja construir uma educação musical na escola básica que contribua com a formação de pessoas mais sensíveis, solidárias, críticas e transformadoras, quando a criação abre a possibilidade de pensar um mundo melhor. (BEINEKE, 2012, p.56).

Portanto, estudos apontam que a música é a mais universal das linguagens. É universal no tempo e no espaço porque desde sempre ocupou lugar preferencial em todas as culturas e todos os povos a utilizam.

O Referencial Curricular Nacional para Educação Infantil traz sua valiosa contribuição ao afirmar que: 
A música é a linguagem que se traduz em formas sonoras capazes de expressar e comunicar sensações, sentimentos e pensamentos, por meio da organização e relacionamento expressivo entre o som e o silêncio. A música está presente em todas as culturas, nas mais diversas situações: festas e comemorações, rituais religiosos, manifestações cívicas, políticas etc. Faz parte da educação desde há muito tempo, sendo que, já na Grécia antiga, era considerada como fundamental para a formação dos futuros cidadãos, ao lado da matemática e da filosofia. A integração entre os aspectos sensíveis, afetivos, estéticos e cognitivos, assim como a promoção de interação e comunicação social, conferem caráter significativo à linguagem musical. É uma das formas importantes de expressão humana, o que por si só justifica sua presença no contexto da educação, de um modo geral, e na educação infantil, particularmente. (BRASIL, 1998, p.45).

A arte no universo infantil possibilita a criança fazer ligações entre as diversas áreas do conhecimento, relacionando-as com o seu dia a dia. Dessa forma, a arte irá aguçar na criança a dimensão do sonho, da comunicação, como: criações musicais, cores, formas, gestos. E por meio dessas percepções, a arte permite que a mesma busque seu próprio modo de ver o mundo ou de dar sentido aos objetos que as rodeiam.

A Arte está presente no cotidiano da vida infantil. Ao rabiscar e desenhar no chão, na areia e nos muros, ao utilizar materiais encontrados ao acaso (gravetos, pedras, carvão), ao pintar os objetos e até mesmo seu próprio corpo, a criança pode utilizar-se das linguagens da arte para expressar experiências sensíveis. (BRASIL, 1998, p. 85).

Mediante a arte, a criança irá realizar sua leitura de mundo ${ }^{1}$, entender o contexto em que vive e relacionar-se com ele, sendo de extrema importância que sua imaginação flua livremente e que seja sempre estimulada com propostas pedagógicas sensíveis, lúdicas, prazerosas e coerentes ao seu universo.

\section{DESENVOLVIMENTO}

Desde muito cedo a criança se comunica e representa seu mundo por meio de diversas linguagens, ela constrói seu conhecimento e antes mesmo de escrever ou ler, já faz uso de linguagens para se expressar.

O ensino da arte, em qualquer nível e, em especial, na Educação Infantil, deve abranger tanto a construção de imagens como contribuir para que as crianças realizem leituras cognoscentes, conscientes e sensíveis das tantas imagens que estão aí, nos meios de comunicação, muitas vezes consumidas passiva e indiscriminadamente por elas. Uma educação do ver

\footnotetext{
${ }^{1}$ Sobre 'leitura de mundo', ver FREIRE, P. A importância do ato de ler: em três artigos que se completam. 1988. 
e do observar significa desvelar nuanças e características do próprio cotidiano e ir além, propondo rupturas com o instituído. (CUNHA, 2012, p. 27).

Neste sentido, refletir sobre a importância da música no contexto educacional, por meio de análises de teóricos relacionados, visando à apreciação e fruição da criatividade e a imaginação da criança, se faz necessário desde a Educação Infantil, pois, a criança aprende sobre a linguagem musical por meio da escuta e exploração do som e suas qualidades. Os professores desta etapa de ensino (da Educação Infantil), mesmo sem serem especialistas em música, podem e devem realizar experiências musicais com as crianças, em que os sons, os ruídos e as percussões produzidas e escutadas tragam contribuições para a formação de sua paisagem sonora ${ }^{2}$, ou seja, permitam que a criança brinque com diferentes tipos de sons, explore e transforme objetos.

Castanho (2000, p. 77) explicita a necessidade de ter "[...] uma educação que estimule nossas crianças a buscar soluções criativas". Para a autora é "[...] preciso que não ensinemos apenas as pegadas de caminhos conhecidos, mas que tenhamos a coragem também de saltar sobre o desconhecido, de buscar a construção de novos caminhos, criando novas pegadas".

Em concordância a Castanho, a autora Susana da Cunha, defende e ainda ressalta que,

[...] a necessidade vital de as crianças terem espaços de criação e experiências múltiplas com as diferentes linguagens expressivas no 'pátio da infância', para que, pelo menos nesse período da vida, possam ter o prazer de viver e de expressar modos singulares de ser e de estar no mundo. (CUNHA, 2012, p. 12).

Portanto, a partir da corroboração da autora acima citada, observa-se que a utilização da Linguagem Musical e a ação docente na formação dos alunos da Educação Infantil são propostas eficazes. Observa-se assim:

A linguagem musical é excelente meio para o desenvolvimento de expressão, do equilíbrio, da autoestima e autoconhecimento, além de poderoso meio de integração social, [...] Integrar a música à educação infantil implica que os professores devam assumir uma postura de disponibilidade em relação a essa linguagem. (BRASIL, 2008, p.49, 67).

Inserir a música como forma de linguagem, é crer na possibilidade de orientar o professor não especialista para esse trabalho e assumir integralmente a importância da música, como atividade presente na construção do conhecimento e da emoção.

\footnotetext{
Paisagem Sonora: 0 autor Murray Schafer, na década de 60, criou o termo em inglês Soundscape, neologismo que quer dizer paisagem. Traduzido para o português, soundscape quer dizer paisagem sonora: qualquer evento sonoro que compõe um determinado ambiente. (SCHAFER, 1991, p.11).
} 
Neste contexto, a arte/educação ${ }^{3}$ é um alicerce para desenvolver essa criatividade, pois a criança como um ser em constante aprendizagem, tem mais facilidade para o senso de observação e em diversas ocasiões, chama a atenção por suas particularidades. Ao utilizar sua liberdade de expressão e de investigação, com o auxílio de seus educadores, conclui-se que suas aprendizagens e seu desenvolvimento, paulatinamente, aumentam sua maneira de expressar e de visualizar o mundo.

A criatividade é considerada como parte essencial do homem, a qual dá equilíbrio à vida, auxiliando-o em seu cotidiano, nas resoluções de problemas e tornando o homem um ser mais criativo. A arte deve ser inserida na educação como forma de estimular o pensamento criador, para que a imaginação da criança e seu intelecto não se separem. (SANS, 2001, p. 24).

O mesmo autor expressa que, "[...] ao desenhar a criança descobre suas próprias normas, numa íntima relação do ver, do saber e do fazer". (SANS, 2001, p. 32).

Já em relação à música, Bréscia (2003, p. 25) afirma que "é uma combinação harmoniosa e expressiva de sons e a arte de se exprimir por meio de sons, seguindo regras variáveis conforme a época, a civilização etc". Por meio dessa combinação harmoniosa de sons, a música funciona como elemento de comunicação e identificação dos povos. A música tem um papel fundamental na educação, pois serve como um elo na transmissão de conhecimentos acumulados pelas gerações passadas. A música aumenta a capacidade de concentração, afina a sensibilidade dos alunos, desenvolve a memória e concentração, além de provocar fortes emoções. Quando realizada no coletivo, traz sentimento de ordem, disciplina, organização, respeito ao outro e a si mesmo.

Por sua vez, a importância da música no processo educacional infantil está no fato de que esta consegue de certa forma trabalhar a personalidade da criança, uma vez que consegue promover o desenvolvimento de hábitos, atitudes e comportamentos que expressam sentimentos e emoções.

Em todo processo educativo confunde-se dois aspectos necessários e complementares: por um lado à noção de desenvolvimento e crescimento (o conceito atual de educação está intimamente ligado à ideia de desenvolvimento); por outro, a noção de alegria, de prazer, num sentido amplo, [...] Educar-se na música é crescer plenamente e com alegria. Desenvolver sem dar alegria não é suficiente. Dar alegria sem desenvolver, tampouco é educar. (GAINZA, 1988, p.95).

\footnotetext{
${ }^{3}$ Será utilizado (/) entre as palavras 'arte' e 'educação', pois, segundo Ana Mae Barbosa (2001) “[...] por a barra significa segundo os linguistas, 'mútuo pertencimento'". 
Da constatação acima, pode-se afirmar que, o acesso à música é necessário ao processo educacional da criança, auxiliando no desenvolvendo da sua criatividade.

Quando esse processo é conduzido por pessoas conscientes e competentes, deixa de ser apenas recreação favorecendo uma rica vivência e estimulando o desenvolvimento dos meios mais espontâneos de expressão. Isso recupera a música à sua condição de linguagem natural, viva, de pensamentos e emoções que conduz a um enriquecimento criativo.

Com a utilização da arte no cotidiano escolar, a criança poderá aprender de forma lúdica, tornando o ambiente escolar mais envolvente e agradável, sendo que o educador terá a possibilidade de contribuir afetiva e cognitivamente para o desenvolvimento da criança. A criança, por sua vez, e por intermédio da arte, representa seus desejos, expressa seus sentimentos e coloca em destaque sua personalidade. Dessa maneira, o educador pode conhecer melhor a criança com quem está trabalhando e, até mesmo, identificar suas dificuldades, pois, a arte pode auxiliar tanto no cotidiano escolar, como no cuidado para que não haja julgamento de certo ou errado, para não interferir na expressão da criança e torná-las inseguras ao soltar sua imaginação e criar.

[...] quando o professor faz correções nas produções infantis do tipo: 'Fulano, não vês que a árvore é verde? Onde está o corpo desta pessoa? Estou vendo que os braços e as pernas saem da cabeça...' Assim, as crianças, desde muito cedo, incorporam os estereótipos e deixam de construir sua própria linguagem, passando a reproduzir e a consumir imagens estereotipadas e impostas pelos adultos. (CUNHA, 2012, p. 16).

A criança desenvolve sua arte dependendo de sua cultura ou a época que está inserida, trazendo consigo seu cotidiano para dentro da sala de aula, enriquecendo a sala de múltiplas formas, dando evidência ao momento atual. O Referencial Curricular Nacional para a Educação Infantil (RCNEI) ressalta que,

A arte da criança, desde cedo, sofre influências da cultura, seja por meio de materiais e suportes com que faz seus trabalhos, seja pelas imagens e atos de produção artística que observa na TV, em revistas, em gibis, rótulos, estampas, obras de arte, trabalhos artísticos de outras crianças etc. (BRASIL, 1998, p. 88).

Quando a criança se expressa de forma espontânea, devolve ao exterior a mesma estimulação que recebe. 


\section{DISCUSSÃO/CONCLUSÃO}

Com a contribuição dos autores, pudemos observar que o processo de aprendizagem faz parte do ser humano e a criatividade faz com que esse processo se desenvolva de forma lúdica nas linguagens artísticas. É necessário cultivar e manter esse processo ativo e estimular a criatividade, a observação e o senso crítico para que as crianças possam ter um olhar amplo e uma visão completa do mundo que as rodeia.

Dessa forma, o ambiente escolar é fundamental para o exercício da arte e da música, como elemento de incitação no processo educativo. A ação do educador, especialmente do educador ligado à educação infantil, deve ser ressaltada por experiências criativas. Tais experiências estimuladoras da criatividade implicam no desenvolvimento das relações e das descobertas pessoais, uma vez que a criatividade e as linguagens artísticas existem nas relações do indivíduo e seu meio.

Portanto, a arte e a música na Educação Infantil possui papel fundamental, pois envolve os aspectos cognitivos, sensitivo, cultural, corporal, entre outros, e as crianças precisam ser estimuladas por meio de todos os seus sentidos. Cabe ao educador (pedagogo) a introdução das linguagens artísticas no universo da criança, despertando-a para o gosto e o interesse pelas diversas ramificações deste mundo fascinante que a arte nos apresenta. Somente assim, construiremos uma sociedade mais sensível, onde cada ser humano seja capaz de valorizar e dar voz as crianças, estes seres tão singulares e cheios de potencialidades a serem desbravadas.

\section{REFERÊNCIAS}

BARBOSA, A. M. Arte-educação: leitura no subsolo. 3. ed. São Paulo: Cortez, 2001.

BEINEKE,V.Aprendizagem criativa e educação musical: trajetórias de pesquisa eperspectivas educacionais.Educação, Santa Maria, v. 37, n. 1, p. 45-60, jan./abr. 2012.

BRASIL, Ministério da Educação e Desportos. Secretária da Educação Fundamental. Referencial Curricular Nacional para a Educação Infantil: Conhecimento de Mundo. v. 3. Brasília: MEC/SEF, 1998.

BRASIL. Ministério da Educação. Referencial Curricular Nacional para a Educação Infantil: introdução. Brasília: Ministério da Educação, 2008. v. 1,2,3.

BRÉSCIA, V.L.P. Educação musical: bases psicológicas e ação preventiva. São Paulo: Átomo, 2003.

CASTANHO, M. E. A criatividade na sala de aula universitária. In: VEIGA. I. P. A. CASTANHO, M. E. (Org.). Pedagogia Universitária: a aula em foco. São Paulo: Papirus, 2000. 
CUNHA, S. R. V. da. As artes no universo infantil. Porto Alegre: Mediação, 2012.

FREIRE, P. A importância do ato de ler: em três artigos que se completam. 22. Ed. São Paulo: Cortez, 1988.

GAINZA, V. H. de. Estudos de psicopedagogia musical. 3. ed. São Paulo: Summus, 1988.

SANS, P. T. C. Pedagogia do desenho infantil. São Paulo: Átomo, 2001. 